\title{
A bioética da proteção e a compaixão laica: o debate moral sobre a eutanásia
}

\author{
Bioethics of protection and the laic compassion: \\ the moral debate on euthanasia
}

Rodrigo Siqueira-Batista ${ }^{1}$

Fermin Roland Schramm ${ }^{2}$

\footnotetext{
${ }^{1}$ Centro Universitário Serra dosÓrgãos(UNIFESO) e Instituto Federal de Educação, Ciênciae Tecnologia do Rio de Janeiro (IFRJ). Curso de Graduação em M edicina (UNIFESO).Av. Alberto Torres 111, Alto. 25964-000 Teresópolis RJ. rsiqueirabatista@terra.com.br ${ }^{2}$ Fundação O swaldo Cruz, Escola Nacional de Saúde Pública, Departamento de Ciências Sociais.
}

\begin{abstract}
Thebioethical debateon euthanasia ("good death") has been classically polarized between the principles of sacredness of life - the argumentation against - and the quality of life, represented by the vicarious principle of respect for autonomy - the argumentation in favor. In both cases the question is built around the pertinence and moral legitimacy - or not - of the individual possibility to decide about the termination of one's own existence, demanding for oneself a good death. Undoubtedly, euthanasia always implies besides the self, the other, who will either carry out the action - or hold to non-action - culminating in the abbreviation of life. To propose a discussion about this last referred issue, based on the bioethics of protection theoretical references and the concept of laic compassion is the scope of the present essay.
\end{abstract}

Key words Bioethics, Compassion, Protection, Euthanasia
Resumo 0 debatebi oético sobrea eutanásia ("boa morte") vem sendo polarizado, classicamente, entre os princípios da sacralidade da vida - argumentação contra - e da qualidade de vida, representado pelo princípio vicário do respeito à autonomia argumentação pró. Em ambos os casos, a questão se constrói em torno da pertinência e da legitimidade moral, ou não, de um indivíduo poder decidir sobre o desenlace de sua própria existência, requerendo para si uma boa morte. Sem embargo, a eutanásia pressupõe sempre, além de um eu, um outro, o qual deverá efetuar a ação - ou ater-se à não-ação que culminará na abreviação da vida. Propor uma discussão acerca deste último ponto, tendo como base os referenciais teóricos da bioética da proteção e o conceito de compaixão laica, é o escopo do pre sente ensaio.

Palavras-chave Bioética, Compaixão, Proteção, Eutanásia 
A eutanásia, boa morte, éum dos assuntos degrande relevância na sociedade contemporânea, o que pode ser "pressentido" pelo atual expressivo número de escritos (acadêmicos e "leigos") e de manifestações artísticas envolven do o tema - como os filmes As Invasões Bárbaras, M enina de O uro e Mar Adentro, que têm apresentado importantes problemas acerca de sua moralidade ${ }^{1-3}$.

No âmbito da bioética laica, a argumentação moral em torno da boa morte tem dado, corretamente, ênfase à autonomia individual do sujeito que decide pela eutanásia ${ }^{4,5}$. Sem embargo, menor atenção tem sido prestada àquel es que se dispõem a praticar 0 ato misericordioso - p. ex., os profissionais de saúde - , cujo objetivo éfindar com um padecimento considerado acima do suportável por um sujeito capaz de reconhecer que sua existência já não vale mais à pena ser "sofrida" e "vivida".

Para preencher esta lacuna, émister queseanalisem criticamente os argumentos morais que sustentam a decisão de um (possível) agente da eutanásia em oferecer a outrem uma boa morte, propondo-se, como referencial teórico para tal análise, as ferramentas da bioética da proteção ${ }^{6}$, âmbito da ética prática que pretende resolver problemas que surgem dos conflitos morais entre os sujeitos, exercendo, para isto, um método consistente em uma tripla função?:

(1) descritiva, ou seja, que se detém em descrever os conflitos da maneira mais racional e imparcial possível, podendo, portanto, ser definida como função propriamente crítica;

(2) normativa, na medida em que se ocupa de resolver tais conflitos, utilizando as ferramentas que podem ser consideradas, por qualquer agente moral racional e razoável, mais adequadas para proscrever os comportamentos considerados incorretos e prescrever aqueles considerados corretos; e

(3) protetora, graças à correta articulação entre (1) e (2) eà sua aplicação a pessoas e contextos concretos, fornecendo os meios capazes de dar amparo suficiente aos envolvidos em tais conflitos, garantindo cada projeto de vida - mesmo que esteimplique em declinar a continuar vivendo - compatível com os demais.

De fato, recuperando-se 0 sentido originário da palavra grega ethos (' $\eta \theta 0 \varsigma)$ - no mundo homérico - de "dar abrigo" - sem olvidar os outros

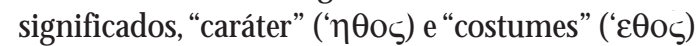
- torna-se clara a intrínseca perspectiva cuidadora e protetora da bioética, visto que todos esses sentidos se referem à capacitação de indivíduos e populações para torná-los moralmente competentes em enfrentar os conflitos que inevitavelmente se dão na vida em comum, depois de garantidas as condições concretas para isso.

É precisamentenestehorizontequeemerge, no coração do debate moral, o conceito de compaixão, enquanto matriz a partir da qual vai se estabelecer uma atitude de amparo a outrem, tal qual o concebível no âmbito da bioética da proteção. N este sentido, Schramm e Floriani, em recenteartigo ${ }^{8}$, expressam que o cuidado/proteção será factível, sempre que aquele que assiste ao enfermo que se esvai, adotar uma atitude acolhedora, ou seja: " [...] tornando-se sensível e conseguindo de modo empático e simpático - perceber a precariedade do momento vivido pelo paciente fragilizado e desamparado [...]" [grifo nosso] ${ }^{8}$

Agir de maneira empática e simpática, ou seja, padecer juntamente, simpatizar e compadecer, é ter compaixão, como, originariamente, na tradição ocidental, com-partilhar $0 \pi \alpha ́$ ós (páthos = paixão, sentimento, afeto arrebatador) do outro. De fato, a compaixão é o alicerce moral de várias tradições sagradas e, em particular, a partir do final do século XIX, do sistema filosófico proposto por Arthur Schopenhauer?.

A identificação da compaixão como fundamento da moral ${ }^{9}$, tal qual estabelecida por Schopenhauer, revelou-se uma excelente tentativa de compor o pensamento oriental - "recebido", pelo filósofo, dos U panixades hindus ${ }^{10}$ - com a tradição ocidental, especialmente no diálogo que este pensador estabelece com o pensamento de Platão ecom a filosofia moral de Kant ${ }^{11}$.

Sem embargo, há dificuldades em sua proposta, na medida em que é pressuposto o desaparecimento da distinção entre o "eu" e o "não-eu" entre al guém e outrem que sofre $\mathrm{f}^{12}$ - para a genuína experiência de compaixão. Tal perspectiva, de inequívoca matriz religiosa (hinduísta e budista), parecemuito difícil - para não dizer impossível de ser colocada em prática no contexto de uma sociedade composta por indivíduos, detentores de direitos e deveres, e que se constituem como sujeitos exatamente na relação (reconhecimento) com um outro separado de si - como é o caso nas sociedades democráticas complexas, laicas e pluralistas, contemporâneas. Em substância, a questão seinstitui nos seguintes termos: como trazer para o campo discursivo próprio da filosofia moral hodierna uma temática intrínseca às sagradas tradições religiosas do Oriente, mas também do Ocidente, como no caso do cristianismo? Tal pergunta pode ser também apresentada deste modo: como enunciar a compaixão em termos laicos? U ma dos problemas a ser trabalhado neste ensaio é a extrema dificuldade, quiçá impossibilidade, de se tratar, no 
âmbito do logos, da Compaixão (com inicial maiúscula) das tradições sagradas; entretanto, pode-se pensar em uma compaixão (com inicial minúscula) laica, inscrita no binômio pensamento-linguagem e, por conseguinte, comunicável eapresentável como referencial teórico para pensar - e agir diante de um homem que opta pela eutanásia. Discutir esta possibilidade em termos da bioética da proteção, tendo como norte o debate bioético sobre a eutanásia, é o escopo do presente artigo.

\section{A compaixão nas tradições sagradas: Compati e Karuna}

Diferentes matrizes religiosas do 0 cidentee do O riente articulam a ação do homem à Compaixão, 0 que se reveste de profundas implicações morais. $\mathrm{Na}$ cultura ocidental, pode-se tomar como exemplos o Judaísmo - como na prática da rahamim, a compaixão sob a forma de misericórdia ${ }^{13}$, tão bem descrita no Salmo $103^{14}$ - e o islamismo - na exortação à sadaca, caridade voluntária em um sentido bem amplo, o qual implica agir em consonância com o bem e apartado do mal - , ao passo que no Oriente é possível recuperar tal horizonte no hinduísmo - algo manifesto no conceito de ahimsa, não violência, instância profundamente defendida por Mahatma Gandhi ${ }^{15}$ - e no taoísmo em uma perspectiva do Wu Wei, caracterizável como não-ação, ou não-intervenção ${ }^{16}$.

A despeito da importância da Compaixão nestas tradições, será no cristianismo e no budismo M ahayana que a exortação para a adoção de um modo de vida compassivo alcançará sua máxima plenitude. Entretanto, por questões históricas e culturais inerentes à emergência e ao desenvolvimento destas duas tradições, a concepção predominante de Compaixão é diferente em ambas, nos termos a seguir.

A dimensão da Compaixão cristã, legado dos ensinamentos do galileu Jesus de Nazaré, pressupõe que se com-partilhe o páthos do outro, o que pode ser sintetizado na máxima "ama ao teu próximo como a ti mesmo". Em última análise, a Compaixão pregada pelo Nazareno traz a dimensão de tomar para si o sofrimento alheio, transcrita, ulteriormente, em latim, como Compati = sofrer $\mathrm{com}^{17}$. Reconhecer a dor do outro e amparálo incondicionalmente - amando-o como a si mesmo - é justamente o espírito manifesto na Parábola do Bom Samaritano: Jesus então contou: Um homem descia de Jerusalém a Jericó, e caiu nas mãos de ladrões, que o despojaram; e depois de $o$ terem maltratado com muitos ferimen- tos, retiraram-se deixando-o quase morto. Por acaso desceu pelo mesmo caminho um sacerdote, viu-o e passou adiante. I gualmente um levita, chegando àquele lugar, viu-o e passou também adiante. M as um samaritano queviajava, chegando àquele lugar, viu-o e moveu-se de compaixão. A proximando-se, atou-Iheas feridas, deitando nelas azeite e vinho; colocou-o sobre a sua própria montaria e levou-o a uma hospedaria e tratou dele. No dia seguinte, tirou dois denários, e deu-os ao hospedeiro, dizendo-Ihe: Trata dele e, quanto gastares a mais, na volta te pagarei. Qual destes parece ter sido o próximo daquele que caiu nas mãos dos ladrões?" Respondeu o doutor: "Aquele que usou de misericórdia para com ele." Então J esus Ihe disse: "Vai, e faze tu o mesmo"14.

O bom samaritano foi capaz de comover-se pelo padecimento do seu próximo, reconhecendo seu grande sofrimento, movendo-se pela Compaixão - um compadecer-se com o sofrimento do outro. N estecaso, ser próximo - eexercer 0 amor em relação a este - baseia-se no mandamento da lei de Deus de amar ao próximo como a si mesmo. Aqui, o si mesmo pode ser concebido no cerne do reconhecimento deuma profunda identidadeexistenteentre um e outro - aquele que sofree aquele que ampara - , legitimada pelo O utro do homem, Deus - a transcendência infinita ${ }^{18}-$, na medida em que ambos são feitos à imagem eà semel hança do Pai ${ }^{14}$. Torna-se claro, pois, que a Compati cristã pressupõe de modo inquestionável, ao prescrever um amor como a si mesmo, um sofrer com entre (criaturas) iguais perante o Criador.

No budismo - modo de vida instaurado a partir do Satori (Iluminação) de Sidharta Gautama, o Buda Shakyamuni, sob a copa da árvore Bodi, no século VI a.C..$^{19,20}$ - , a genuína Experiência, ou adoção de um novo ponto de vista como enfatizado por Suzuki, ${ }^{21}$ inclui dois movimentos distintos, mas intrinsecamente relacionados: o desapego total e a acolhida incondicional. 0 primeiro inscre ve-se na Com-preensão da efemeridade da vida e da interdependência de todas as coisas; o segundo manifesta-se como Compaixão - Karuna (sâncrito); Thugs rje(tibetano) - , a plena recepção de todos os seres, sem julgamento, como expresso nos dois excertos a seguir:

Equiparar o "nós" e os "outros" significa desenvolver a atitudee compreensão de que, "assi $m$ como desejo felicidade equero evitar o sofrimento, o mesmo se dá com os outros seres humanos, que são infinitos no espaço: também eles desejam felicidade e querem evitar o sofrimento ${ }^{22}$.

Compaixão significa oferecer morada às pessoas, abrir as portas até então fechadas para elas, pergun- 
tar mais que responder. Significa tornar-sealtamente sensível à situação e aos sentimentos da outra pessoa. Significa ouvir com todo o seu ser e dar, se for possível, o que seja relevante e apropriado para 0 relacionamento, não 0 avaliando com julgamentos próprios ${ }^{23}$.

De acordo com o cânone budista, a plenitude da Compaixão é vivenciada pelos Bodhisattvas, seres extraordinários que são fortemente motivados e movidos pela Compaixão, [e que] prometem alcançar o estado de onisciência em prol da felicidade de todos os seres sencientes ${ }^{24}$, nos seguintes termos: 0 Compêndio do Perfeito Dharma diz o seguinte: "O Buda, um Bodhisattva não deve se dedicar a muitas práticas. Se um Bodhisattva se ativer a um único Dharma e apreendê lo com perfeição, ele possuirá todas as qualidades do Buda na palma de sua mão. E sevocêperguntar o queéesseúnico $D$ harma, é uma grande compaixão" 24 .

O novo ponto devista mencionado por Suzuki, em sua preleção sobre o Satori, pressupõe a aquisição de "um olhar intuitivo no âmago das coisas, em contraposição à sua compreensão intelectual e lógica"21, no qual está inscrita a superação da mente dualística e a percepção genuína de que o "mundo das coisas" (seres), suas formas e conteúdos, são ilusórios. Neste sentido, são eliminadas "as distinções dualísticas como eu/você, verdadeiro/falso, sujeito/objeto, a fim de chegar a uma essência da vida não condicionada por palavras e conceitos" ${ }^{\prime \prime}$. Os efêmeros seres temporo-espacialmente localizados não são em si mesmos, somente havendo o "espaço ilimitado, infinito", um imenso e profundo Vazio, "de onde todas as coisas emanam e para a qual retornam"19. Tal é a compreensão da Verdadeira N atureza Búdica, como retorno à casa, pura fluência para a lídima Compaixão: Não existe uma divisão ou barreira entre o si mesmo e os outros, não há mais quaisquer sentimentos de alienação, medo, ciúmeou ódio pelos outros, pois já se sabe e está comprovada a evidente realidade de que não existe nada separado do si mesmo e, portanto, nada a temer. Esta compreensão naturalmente resulta na "verdadeira compaixão". As pessoas e coisas não são mais vistas como separadas, mas como o próprio corpo ${ }^{19}$.

Compreensão e Compaixão desdobram-se, no âmbito da práxis, na co-operação entre os seresno sentido de agir junto, operar junto - , os quais passam a ser vistos como parceiros, capazes de compartilhar o espaço vital25, em uma lídima aceitação do mundo da vida. A Karuna budista é, assim, a acolhida incondicional.

A despeito das diferenças entre Compati e Karuna, ambas pressupõem uma situação de identidade entre homens (cristianismo) e entre viventes (budismo), capaz de tornar a Compaixão um fundamento que emerge espontaneamente quando se está defronte a um outro que padece. Esta identidade entre os seres humanos passou à tradição ocidental, pelas "mãos" do cristianismo, como ideário de igualdade - bem como de liberdade e fraternidade - , tal qual discutido em outras oportunidades $^{4,26}$. De fato, já nas primeiras comunidades cristãs, celebrava-se a igual dade entre os homens, na proporção em que estes, por terem sido criados como almas individuais, à imagem e semelhança deDeus, pertencem, em igual medida, ao plano eà obra do Pai27.

Com base nestas considerações, pode-se propor que a identidade entre viventes, tão peculiar às tradições sagradas - inscrita em Deus ${ }^{14}$ ou na Natureza Búdica ${ }^{28}$ - pode ser pensada, em termos seculares, como igualdade, entre homenslançados no tempo - ou seja, que nascem, sofrem e morrem (como será detal hado adiante) - , detentores de direitos e correspondentes deveres perante as sociedades. Assim, a identidade que funda a Compaixão poderia ser redimensionada e discutida em termos de igualdade, esta última capaz de legitimar uma concepção de compaixão laica, aplicável ao âmbito da ética eda bioética. Adiante, tentar-se-á demonstrar em que medida isto é pensável (e possível).

$M$ as, em que consiste esta igualdade? Colocar tal questão não é simples, como se torna perceptível nos grandes debates sobre igualdade, equidade ejustiça, ao longo da história do pensamento ocidental, desde os gregos ${ }^{29-31}$. Uma das maneiras de tratar a questão éinterrogando, com Amartya Sen, sobre o que deve ser igualado ${ }^{32-34}$. A resposta dada a tal indagação será o ponto de partida para se propor, em termos bioéticos, um conceito de compaixão laica.

\section{Compaixão laica ebioética da proteção}

O economista e filósofo indiano Amartya Kumar Sen propõe, como ideário de justiça, a igualdade de capacidades - as quais se referem à liberdade efetiva que um indivíduo tem de escolher diferentes tipos de vida, entre as alternativas possíveis, 0 que torna factível a opção por realizar distintos grupos de funcionamentos, aquilo que logra fazer um vivente 35 - entre os membros de uma dada sociedade. Tal igualdade representa uma resposta cogente - dada especialmente a J ohn Rawls ${ }^{36}$ - , sendo capaz de articular, de maneira complexa, os princípios morais de justiça e autonomia ${ }^{34}$.

A definição de Sen pressupõe algo óbvio, mas 
não menosimportante de seexplicitar, pois a igualdade de capacidades só faz sentido para os viventes. Ora, um vivente tem duas dimensões inextirpáveis - nascer emorrer - , como lembram os médicosfilósofos Empédocles de Agrigento e Alcmeão de Crótona: "Ai, pobre e infeliz raça dos mortais, de que discórdias e lamentos vós nascestes!"37

Alcmeão atribui a morte dos homens ao fato denão serem capazes de unir o início ao fim - um dito sagaz se lhe atribuirmosum sentido vago, sem buscar imputar-Ihe um caráter de precisão $0^{38}$.

Neste sentido, pode-se conceber que há uma igualdade radical - em termos de suas mais profundas e íntimas raízes - entre tudo o que vive: nasce-se e morre-se, não existindo vida que não tenha "passado" por um vir-a-ser e que, necessariamente, não acabe por se esvair em um deixardeser - quiçá como na "fórmula" de Anaximandro de $M$ ileto, para o qual do apeiron (apeiron = ilimitado) tudo emerge a eletudo torna ${ }^{37}$. A partir de tal constatação, torna-se possível situar no mesmo plano - ou plano de imanência - todos os viventes, espaço-temporalmente limitados.

A despeito desta óbvia condição que perpassa todos os vivos, há um terceiro matiz de igualdade, o qual pode ser pensado em relação aos seres sencientes, incluído o homem: a possibilidade de sofrer. 0 padecimento relaciona-se à fragilidade própria da vida - um simples suspiro da eternidade - , efêmera e precária, vulnerável e corruptível. Destemodo, compreende-seque existir é(ou pode ser) sofrer. Tal é a constatação que ressoa na própria estruturação da vida humana, enquanto horizonte que perpassa as mais díspares culturas ${ }^{39}$. Ademais, o padecimento seatrela inextricavelmente à situação presente - afinal, só é possível vivenciar o agora: o passado só se faz desde que "(re)atualizado" no presente; quanto ao futuro, só passa a ser ao manifestar-se como atual - e, nisto, a espécie humana é solidária aos demais seres sencientes, os quais, até onde se saiba, não conhecem o que passou ou o que esta por vir, situandose em um eterno presente - o qual, pode muito bem ser preenchido, em seus dias e noites, pela dor e pelo martírio.

Reconhecer que a vida tem como pressupostos, necessários, o nascimento e o passamento, acrescentando-se a isto, na experiência humana de existir, a contingência do sofrimento, é o primeiro passo para a delimitação da compaixão em termos seculares. Mas, é mister compreender que a igualdade expressa nos termos acima colocados pode ser concebida, à semel hança do descrito para as tradições sagradas, como manifestação de uma identidade profunda, a qual torna interligados - einterdependentes - os partícipes do imenso palco da existência, isto é, suas respectivas condições de viventes: Considerar que a felicidade e a infelicidadefazem parte da não-permanência vai despertar em nós, ao mesmo tempo, uma qualidade de compaixão e uma qualidade de presença junto aos sofrimentos do outro $[\ldots]^{40}$.

Destemodo, a compaixão se estabelecena compreensão de uma inquestionável situação de igualdade que é pertinente à vida - ou seja, nascer, sofrer (em relação aos seres sencientes) e morrer. Tal com-preensão permite ao sujeito se colocar, em exato pé de igualdade, em relação ao outro, 0 qual pode ser acolhido, compassivamente, em um movimento de deslocamento do "eu" em direção ao "outro" (não a superação das distinções entre ambos, mas, sim, um deslocamento de dupla dire ção), a partir de uma deferência irrestrita à inserção deste último no mundo ${ }^{41}$. De fato, ser compassivo não significa adotar um posicionamento paternalista - ou seja, decidir, autoritariamente, acerca do que é melhor para outrem - , fundamentado em um mero sentimento de pena ou comiseração, mas, sim, desenvolver e praticar um amplo respeito à existência, na medida em que se acolhe, incondicionalmente, aquele que sofre, ativamente, em seu âmago:

Enquanto o espaço perdurar

E enquanto os seres sencientes permanecerem,

Possa eu também permanecer

Para libertar do sofrimento todos os seres sencientes ${ }^{24}$.

Com base nestas conjecturas, uma "fórmula" geral para a compaixão laica poderia ser assim expressa:

(1) todos os seres vivos são finitos e perecíveis, estando inscritos no tempo, subservientes, então, aos ditames do nascimento e da morte;

(2) dentre os vivos, há aqueles capazes de padecer, os sencientes, os quais agem para evitar (ou minimizar) seus respectivos sofrimentos;

(3) o reconhecimento de (1) e(2) impõequese aceite $a$ igualdade radical e irrestrita que perpassa todos os seres;

(4) a atitude diante de um igual que sofre só pode ser de amparo, na medida em que, em última análise, nestes momentos cruciais, a compreensão de (3) torna inconsistente que o eu se veja como completamente independente (e apartado) do outro que sofre;

(5) amparar tal vivente em martírio - havendo distinção, mas não separação, entre aquele que "recebe" e aquele que é "recebido" - é acolher a igualdade radical imanente à condição de vivente;

(6) acolher/proteger o outro, em tal circunstân- 
cia, só pode ser obtido sem julgamento, ou seja, a partir da recepção incondicional de sua situaçãono-mundo (a despeito dos sofrimentos, desejos e decisões autônomas, em relação à sua própria existência);

(7) 0 acolhimento/proteção assim expresso é um genuíno ato de compaixão.

Toda a argumentação, apresentada nos sete passos acima, tem como horizonte a proteção do outro, a partir do entendimento de queo ethos, a "morada", só se atualiza nas relações entre as pessoas. Assim, agir por compaixão laica é, na verdade, proteger 0 outro - especialmente em situações de de samparo, nas quais sua autonomia esteja muito limitada - , dando-Ihe condições para exercer um mínimo de autodeterminação em relação às (graves) decisões a serem tomadas. Esta é, precisamente, uma das proposições da bioética da proteção, que pode ser vista como 0 ato primordial e que, devidamente pensado, pode servir como referencial teórico-prático, pois pretenderesgatar aquelequeé, provavelmente, o significado originário da palavra grega ethos, que tem justamente o sentido de "amparo", "guarita" e "abrigo"; em suma, de proteção7.

Vale ressaltar que esta proteção pode ser aplicada:

(1) às relações interpessoais - médicos-pacientes, por exemplo;

(2) às relações entreEstado e cidadãos - como aquelas que se estabelecem em saúde pública entre formuladores e gestores de políticas sanitárias e a população destinatária de tais políticas - no quea bioética da proteção pode ser aproximada da concepção dehospitalidadeincondicional defendida por Jacques Derrida em suas últimas obras ${ }^{42-44}$; e

(3) às relações entre o homem, os demais seres vivos e o planeta - como seria o caso de políticas ambientais que visassem proteger o óikos ("casa comum") indispensável à sua sobrevivência contra catástrofes.

Inscrevem-se, no primeiro caso, os aspectos relativos ao debate moral sobre o fim da vida, no contexto da bioética da proteção e da compaixão laica.

\section{Eutanásia: um ato decompaixão laica}

A tomada de consciência da própria finitude pare ce ter ocorrido antes mesmo do aparecimento do H omo sapiens sapiens, havendo indícios de que 0 H omo sapiens neanderthalensis, há mais de 60.000 anos, já realizava rituais de sepultamento ${ }^{45}$. Deste ponto de vista, é constitutiva à espécie humana a compreensão de que a vida se extinguirá, inexora- velmente, na morte, tal qual tematizado nas diferentes manifestações da cultura - pode-semencionar as narrativas míticas, as religiões, a filosofia, a ciência ea arte $^{46}$.

Assim, a morte - uma das condições de igualdade entre os viventes, tal qual o acima descrito é o destino da vida, mantendo-se, sempre, como possibilidade - afinal, o passamento éuma "porta que está sempre aberta". Tal entendimento possibilita que uma pessoa cognitivamente competente, racional e razoável, possa tomar a decisão autônoma de morrer - com todos os problemas que a autonomia possa ter ${ }^{4,26,47}$ - , quer para mitigar os terríveis sofrimentos de uma moléstia incurável a qual 0 obriga "a se reconhecer mortal" 48 - , quer por perceber sua existência como insuportável e indigna de ser vivida (ou padecida) - , como nas palavras do personagem de Ramón Sampedro, no filme $\mathrm{M}$ ar Adentro: [...] eu quero morrer porque a vida para mim, neste estado [...] não é digna. Entendo que outros tetraplégicos possam se ofender quando eu digo que a vida assim é indigna [...] M as, eu não julgo ninguém. Quem sou eu para julgar os que querem viver? Por isso, peço que não julguem a mim ea quem me ajudar a morrer [...] "49

Nesta situação de amargura, na qual viver é um martírio para além de todas as forças do titular da existência - de acordo com sua perspectiva de não querer, de modo algum, continuar "vivendo" (como vociferado por Sampedro) - , qual seria a melhor forma de agir?

(1) Tentar consolar - quiçá por meio dos cuidados paliativos ${ }^{50}-0$ que é, muitas vezes, inconsolável (afinal, o adequado controle da dor, da dispnéia, da ansiedade e de quaisquer outras manifestações mórbidas pode não ser suficiente para que um homem deixe de desejar, para si, o consolo da morte)?

(2) Impor um "renascimento" forçado, a cada momento, pelo tratamento inconsequente e contra a vontade do enfermo, adotando-se as nefastas e inclementes obstinação terapêutica e distanásia? ${ }^{51}$

(3) Abandonar o homem que sofre, deixandoo entregue a sua própria (má e desgraçada) sorte?

(4) Oferecer-Ihe a possibilidade de acabar com seu sofrimento, possibilitando o fim do martírio através de uma ansiada (e desejável, de seu ponto de vista) boa morte - a eutanásia?

Entre as opções acima, qual aquela que poderia ser considerada como inscrita no acolhimento de um ser que padece? A resposta a tal questão vai emergir, precisamente, na relação entre aquel e que cuida e aquele que é cuidado: se a decisão for realmentenão permanecer vivendo, acolher tal disposição é, efetivamente, um ato de compaixão. Como 
apresentado, tal acolhimento pressupõe o não-julgamento do outro - algo absolutamente explícito na declaração de Ramón, em M ar Adentro - , mas, sim, e tão somente, sua aceitação, o amparo de sua condição de vivente ${ }^{25}$, caracterizando o movimento de recebêlo sem preconceitos ecom profunda responsabilidade $e^{40}$.

\section{Antecipando possíveis críticas}

A despeito de sua fecundidade, a utilização da compaixão como referencial teórico nas discussões éticas ebioéticas, recebeu - econtinua recebendo algumas críticas, as quais devem, outrossim, ser discutidas, dentro da perspectiva própria de uma práxis compassiva, merecendo destaque (1) o paternalismo, (2) a pusilanimidadee (3) a inatingibilidade ${ }^{52-56}$.

\section{Paternalismo}

Boa parte da acusação de "paternal ista", dirigida à ética de matriz compassiva, podeser descrita como crítica às rel ações de poder. Em seu livro D a compaixão à solidariedade ${ }^{53}$, Sandra Caponi caracteriza como atinentes à "lógica da compaixão", os seguintes aspectos: [a lógica da compaixão] parece instaurar uma modalidade peculiar de exercício de poder que se estrutura a partir do binômio servir-obedecer, multiplicando, assim, a existência de relações dissimé tricas, entre quem assiste e quem é assistido ${ }^{53}$.

Tal consideração se estriba - como reconhece a própria autora - na crítica nietzschiana, dirigida, sobretudo, ao cristianismo, ao budismo e ao pensamento de Schopenhauer. Assim, coube ao fiIósofo de Além do bem edo mal ${ }^{54}$ eda Genealogia da moral ${ }^{55}$, a seguinte formulação: "N ossos benfeitores, ainda mais que nossos próprios inimigos, diminuem nosso valor e nossa vontade" 56 .

Em tal situação - segundo argumenta N ietzsche - instaura-se uma profunda assimetria entre um e outro, estando 0 assistido em flagrante situação de inferioridade. Mas é precisamente neste contexto que o conceito de compaixão laica presentemente construído ganha maior expressão, na medida em que mesmo diante de uma circunstancial assimetria - como no caso da interação entre médico e paciente, por exemplo - , a relação é (ou deveria ser) construída entre sujeitos lançados no tempo, e, portanto, compartilhantes de uma igualdade inextirpável, a qual os torna inseparáveis do ponto de vista de sua origem (nascimento), finitude (morte) esensibilidade (sofrimento). Ademais, retomando a perspectiva protetora da bioética, 0 objetivo nestas circunstâncias é facilitar que o outro em situação de desamparo possa ser acolhido, até que o exercício de sua autonomia possa ser restabelecido.

Em tal caracterização, torna-se claro quea compaixão não se estabelece necessariamente dentro de um contexto paternalista - ou seja, entre alguém "superior" e "alguém" inferior - , como parece ter sido a (equívoca) interpretação de Capo$\mathrm{ni}^{53}$, na medida em que a acolhida incondicional do outro deve se dar, mantendo em alta conta os genuínos propósitos de vida do sujeito amparado. É por isso quea compaixão laica se estabel ece entre compartilhantes de uma radical e inquestionável igualdade, ou seja, só há compaixão entre iguais.

\section{Pusilanimidade}

A moral inscrita em um ethos compassivo vem sendo acusada de ser uma "ética para fracos" e "pusilânimes": "[...] a figura do homem piedoso é al guém que não pode tolerar qualquer tipo de dor, por menor que seja, que não pode desfrutar ou aprender com sua solidão [...]"53.

De acordo com este ponto de vista, a motivação para uma ação compassiva poderia ser a repulsa à infelicidadeeao padecimento, a negação do alcance que o sofrimento pode ter para uma dada pessoa, como no entender deNietzsche: [...] tudo quepode ser vinculado à infelicidade, não preocupa a esse caro compassivo, ele quer socorrer e não pensa que existe uma necessidade pessoal da infelicidade; que tu e eu temos necessidade pessoal do medo, das provações, do empobrecimento, das vigílias, das aventuras, dos riscos, das transgressões e de seus contrários e mesmo, para me exprimir de modo místico, que o caminho de nosso céu atravesse sempre a voluptuosidade de nosso próprio inferno ${ }^{56}$. [grifo do autor]

Ora, se para a formulação da compaixão laica épreciso, justamente, reconhecer a impermanência de todas as coisas e o sofrimento que se manifesta em toda a existência senciente, como o homem compassivo pode ser caracterizado enquanto "alguém que não pode tolerar qualquer tipo de dor" - ou seja, um fraco e pusilânime? Há uma questão de compreensão em relação à verdadeira natureza da compaixão, concebida em termos seculares. Ademais, pode-se responder a $\mathrm{Nietzsche,} \mathrm{em} \mathrm{concor-}$ dância com Sérgio Fernandes ${ }^{57}$ : Não há compaixão sem comprensão. [...] A Grande Compaixão tem sido demasiado facilmenteconfundida com enternecimento frouxo, mas a ternura do coração é ríspida, senão afiada, cortante, penetrante como a espada. "Tornar-se vulnerável", "sem defesa", ou "tornar-se como 
as criancinhas", no sentido de compreender que seé, antesdemais nada, criatura, apesar decriadora como o Criador, é algo que exige tamanha resistência que faria tremer de medo um super-homem ${ }^{57}$.

A compaixão nada tem a ver com a fraqueza apontada por Nietzsche e por Caponi, na medida em que a igualdade só pode ser reconhecida em um contexto em que se identifica o sofrimento como intrínseco à existência de todos e de cada um. A moral do cordeiro, tão comentada por $\mathrm{Ni}$ etzsche na Genealogia da M oral, nada tem a ver com a atitude autenticamente compassiva. Só há compaixão entre tenazes.

\section{Inatingibilidade}

Seria a compaixão atingível pelo homem das sociedades democráticas e plural istas contemporâneas? Nos termos apresentados em relação à Compaixão inerente às tradições sagradas - budista $e$ cristã - , quase certamente não, de acordo com as considerações apresentadas no início deste ensaio. Sobre isto, pode-se interpor um excerto de N ietzsche, transcrito de A gaia ciência: $O$ que nos faz sofrer de modo mais profundo e pessoal éininteligível einatingível a quase todos os outros; nisto que permanecemos ocultos a nosso próximo mesmo quando coma conosco na mesma mesa ${ }^{56}$. [grifo nosso]

0 aforismo de N ietzsche é elucidativo, trazendo em seu bojo a possibilidade de compreensão da (aparente) aporia da inatingibilidade: a palavra quase. Por que não todos? Provavelmente, porque al guns são capazes, efetivamente, de reconhecer 0 sofrimento como constitutivo da existência humana - e dos demais seres sencientes - , independente do motea partir do qual este se manifesta perdas, doenças, traumas e outros. $\mathrm{Na}$ verdade, a dificuldade está, precisamente, em reconhecer-sea inegável igualdade que perpassa toda a existência, nos termos presentemente pontuados, e reiterados por David Bohm ${ }^{58}$ : [é] enganoso e sem dúvida errado supor, por exemplo, que cada ser humano é uma realidade independente que interage com outros seres humanos e com a natureza. Em vez disso, todos esses são projeções de uma totalidade única. [...] Deixar de levar isso em consideração deve, inevitavelmente, levar aquele que o deixa a uma confusão séria e persistente em tudo o que faz ${ }^{58}$.

Uma vez com-preendido tal pressuposto, a inatingibilidade, simplesmente, cessa de ser um problema. N asce-se, sofre-se e morre-se e neste ciclo, samsara em termos budistas, expressa-se a impermanência inerente à ordem de toda a forma de vida. A compaixão é universal.

\section{Considerações derradeiras}

A experiência deviver um profundo sofrimento como, por exemplo, estar morrendo vitimado por uma doença grave eincurável, ou, ainda, estar "encarcerado" no próprio corpo (por uma tetraplegia e/ou uma doença degenerativa) - , pode se constituir em algo insuportável para o titular da existência. Nestes casos, quando o desespero e a agonia dão o tom, preenchendo completamente os dias e noites, a interrupção - definitiva - do martírio torna-se, muitas vezes, a melhor (ou única) opção para aquele que se esvai, de tal sorte que uma "boa morte", a eutanásia, pode se constituir em uma genuína libertação $0^{59,60}$.

Aquiescer a tal anseio, fornecendo os meios para a prática da eutanásia - ou, efetivamente, concre tizando-a com as próprias mãos - pode ser moralmentejustificável em tais circunstâncias? Tal foi a questão trabalhada neste artigo, tomando como esteio a idéia de Compaixão, recuperada a partir de seu sentido originário nas tradições sagradas especialmente o budismo - , mas redimensionada na ordem discursiva própria da filosofia ocidental, agora como compaixão laica em íntima relação com os referenciais teóricos da bioética da proteção. Assim, pois, é argumentativamente cogente afirmar que agir por compaixão implica:

(1) a com-preensão de que (a) nascer e morrer são dimensões inextirpáveis de qualquer vida - 0 quetorna os viventes possuidores de uma igual dade inquestionável - , (b) inscrita no tempo e, por conseguinte, impermanente, (c) sujeita a sofrimentos das mais diferentes ordens e, eventualmente, reconhecíveis como não mais toleráveis por seres racionais e razoáveis e,

(2) a ação de acolhimento incondicional daquele que sofre, não-o-julgando, a partir do oferecimento de uma boa morte que lhe permitirá encerrar seus dias com dignidade.

Esta seria uma possível síntese da inscrição da compaixão laica no debate moral sobre a eutanásia, entrando em cena enquanto horizontecapaz de permitir o abrigo daquele que padece, garantindo sua autonomia, no sentido de tornar fato a disposição defenecer em paz esem dor - caracterizando uma boa morte. Eis a acolhida incondicional .

Ademais, se se reconhece que, nestes termos, há uma atitude de amparo à autonomia do indivíduo decidido a morrer, garantindo o seu "exercício" em um momento defragilidade, éfactível conceber, claramente, que, em última análise, a compaixão pode ser pensada como uma fundamental característica da bioética da proteção. De fato, o 
alcance da compaixão laica coincide com o próprio ethos do mundo homérico - agora dimensionado em óikos - , na medida em que se institui como morada, acolhida incondicional da experiência de viver, quiçá reiterando sua beleza, o que pode, perfeitamente, significar, como nas palavras de Platão, aprender a morrer...

\section{Colaboradores}

R Siqueira-Batista concebeu o presente artigo, tendo elaborado sua estruturação originária e trabaIhado na formulação do conceito de compaixão laica; FR Schramm participou como um leitor crítico do manuscrito, contribuindo, decisivamente, para as questões relativas à bioética da proteção.
Referências

1. Patterson R, George K. Euthanasia and assisted suicide: a liberal approach versus the traditional moral view. J Law Med 2005;12(4):494-510.

2. Gomes EC, Menezes RC. Aborto e eutanásia: dilemas contemporâneos sobre os limites da vida. Physis 2008; 18(1):77-103.

3. Wolf SM. Physician-assisted suicide. Clin Geriatr M ed 2005; 21(1):179-192.

4. Siqueira-Batista R, Schramm FR. A eutanásia e os paradoxos da autonomia. Cien Saude Colet 2008; 13(1):207-221.

5. Breslin JM. Autonomy and the role of the family in making decisions at the end of life. J Clin Ethics 2005;16(1):11-19.

6. Schramm FR, Kottow M. Principios bioéticos en saIud pública: limitaciones y propuestas. Cad. Saude Publica 2001; 17(4):949-956.

7. Schramm FR. Bioética da proteção: justificativa e finalidades. Iatrós - Cadernos de Filosofia, Saúde e Cultura 2005; 1:121-130.

8. Schramm FR, Floriani CA. Bioética em cuidados paliativos. No prelo 2005.

9. Schopenhauer A. Sobre o fundamento da moral. São Paulo: M artins Fontes; 2001.

10. Janaway C. Schopenhauer. São Paulo: Loyola; 2003.

11. Schopenhauer A. 0 mundo como vontade e representação. São Paulo: Editora da UNESP; 2005.

12. Barboza J. Schopenhauer. Rio de Janeiro: Jorge Zahar; 2003.

13. Bentsion S. Torah, Etz Chaim (Torah, Árvore da Vida). U m chamado para o despertar de Judeus e não-Judeus. [acessado 2005 out]. Disponível em: http://www. yeshuachai.org/forum/viewtopic.php? $p=16890 \&$ sid=f9a9d8337e7e4f11d76461a 4435bfed7

14. Bíblia Sagrada. 3a ed. Lisboa: Difusora Bíblica; 1968.

15. M ahatma Gandhi. Handeln aus dem Geist. Freiburg: Herder; 1977.

16. Lao Tsé. Tao Te Ching: o Livro do Caminho e da Virtude. 4ạ ed. São Paulo: Mauad; 1999.

17. Santo Agostinho. Confissões. São Paulo: Nova Cultural; 2000 .

18. Pascal B. Écrits sur la Grâce. Paris: Lafuma/Sueil; 1963.

19. Scott D, Doubleday T. 0 livro de ouro do Zen. $2^{a}$ ed. Rio de Janeiro: Ediouro; 2000. 
20. Siqueira-Batista R. Zen-budismo: um primeiro escrito. Iatrós - Ensaios de Filosofia, Saúde e Cultura 2005; 1:5-36.

21. Suzuki DT. Introdução ao Zen-budismo. 3a ed. Rio de Janeiro: Civilização Brasileira; 1973

22. Dalai Lama. 0 mundo do Budismo tibetano: uma visão geral de sua filosofia e prática. Rio de Janeiro: Nova Fronteira; 2001.

23. Brandon D. Ajuda pelo Zen-Budismo. São Paulo: Pensamento; 1976.

24. Dalai Lama. Os estágios da meditação. Rio de Janeiro: Rocco; 2001.

25. Boff L. Saber Cuidar. Ética do H umano - Compaixão pela Terra. 8a ed. Petrópolis: Vozes; 2002.

26. Schramm FR. A autonomia difícil. Bioética 1998; 6(1):27-37.

27. Jaeger W. Paidéia: a formação do homem grego. São Paulo: M artins Fontes; 1995

28. Gyatso GK. Compaixão universal. Rio de Janeiro: Jorge Zahar; 1996.

29. Platão. A República. 3a ed. Lisboa: Fundação Calouste Gulbenkian; 1980.

30. Aristóteles. Ética a Nicômaco. Brasília: Ed. Universidade de Brasília; 1985.

31. Aristotle. The Politics and the Constitution of Athens New York: Cambridge University Press; 1996.

32. Sen A. Equality of what? In: M cM urrin S, editor. Tanner Lectures on Human Values. Cambridge: Cambridge University Press; 1980. p. 34-48.

33. Sen A. Desigualdade reexaminada. Rio de Janeiro: Record; 2001.

34. Siqueira-Batista R, Schramm FR. A saúde entre a iniquidade e a justiça: contribuições da igualdade complexa de Amartya Sen. Cien Saude Colet 2005; 10(1): 129-142.

35. Sen A. Capacidad y Bienestar. In: Nussbaum M, Sen A, coordenadores. La calidad de vida. Ciudad do Mé xico: Fondo de Cultura Económica; 1996. p. 54-83.

36. Rawls J. U ma teoria da justiça. $2^{a}$ ed. São Paulo: Martins Fontes; 2002.

37. Kirk GS, Raven JE, Schofield M. Os filósofos pré-socráticos: história crítica com seleção de textos. Lisboa: Fundação Calouste Gulbenkian, 1994.

38. Aristote. Problèmes. Paris: Belles Lettres; 1991-1994.

39. Campbell J. Temas mitológicos na arte e na literatura criativa. In: Campbell J. M itos, sonhos e religião. Rio de Janeiro: Ediouro; 2001.

40. Leloup J-Y. A montanha no oceano: meditação e compaixão no budismo e no cristianismo. Petrópolis: Vozes; 2002.
41. Boff L. Princípio de compaixão e cuidado. 3a ed. Petrópolis: Vozes; 2001.

42. Derrida J. A solidariedade dos seres vivos [entrevista com Evandro Nascimento]. Folha de São Paulo 2001, 27 mai; p. 12-16.

43. Derrida J. Voyous. Galilée: Paris; 2003.

44. Schramm FR. A moralidade da prática de pesquisa nas ciências sociais: aspectos epistemológicos e bioéticos. Cien Saude Colet 2005; 9(3):773-784.

45. Campbell J. As transformações do mito através do tempo. 10a ed. São Paulo: Cultrix; 1997.

46. Zaidhaft S. M orte e formação médica. Rio de Janeiro: Jorge Zahar Editor; 1997.

47. Kottow M. Enseñando las paradojas de la autonomía. Rev Bras Edu M éd 2000; 24(3):40-45.

48. Canguilhem G. Escritos sobre a medicina. Rio de Janeiro: Forense U niversitária; 2005.

49. Amenábar A. Mar Adentro. Espanha: 20th Century Fox/Fine Line Features; 2004.

50. Floriani CA. Princípios éticos aplicados aos cuidados paliativos. Iatrós - Ensaios de Filosofia, Saúde e Cultura 2005; 1:157-166.

51. Siqueira-Batista R. A ressurreição de Frankenstein: uma metáfora das Unidades de Terapia Intensiva contemporâneas. In: Schramm FR, Rego STA. Bioética, riscos e proteção. Rio de Janeiro: Editora da UFRJ; 2005.

52. Van Delden JJ. The unfeasibility of requests for euthanasia in advance directives. J M ed Ethics 2004; 30(5):447-451.

53. Caponi S. Da compaixão à solidariedade: uma genealogia da assistência médica. Rio de Janeiro: Fiocruz; 2000.

54. Nietzsche F. Além do bem e do mal. 1ạ ed. São Paulo: Companhia das Letras; 1998.

55. Nietzsche F. Genealogia da moral. 2ª ed. São Paulo: Companhia das Letras; 1999.

56. Nietzsche F. A gaia ciência. São Paulo: Hemus; 1981.

57. Fernandes SLC. Ser humano: um ensaio em antropologia filosófica. Rio de Janeiro: Mukharajj; 2005.

58. Bohm D. A totalidade e a ordem implicada. U ma nova percepção da realidade. São Paulo: Cultrix; 1992.

59. Siqueira-Batista R. Eutanásia e compaixão. Rev Bras Cancerol 2004; 50(4):334-340.

60. Siqueira-Batista R. Quantum bioethics: ethics for all beings. Cien Saude Colet 2008; 13(3):611-613.

Artigo apresentado em 30/08/2006

Aprovado em 24/10/2006

Versão final apresentada em 20/01/2007 